\title{
DOMINANT LETHAL MUTATIONS INDUCED IN MALE MICE BY METHYL METHANESULPHONATE
}

\author{
M. PARTINGTON and A. J. BATEMAN \\ Paterson Laboratories, Christie Hospital and Holt Radium Institute, Manchester, 20
}

Received 25.x.63

\section{INTRODUCTION}

INFORMATION on the mutagenic activity of monofunctional alkylating agents in mammals is somewhat limited, most attention having been focused on the polyfunctional compound, triethylenemelamine (Cattanach and Edwards, I958; Cattanach, I959; Bateman, 1960) and on nitrogen mustard (Falconer, Slizynski and Auerbach, 1952).

The simple straight-chain monofunctional compounds methyl methanesulphonate (MMS), methyl ethanesulphonate (MES) and ethyl methanesulphonate (EMS) have been shown to have highly specific effects on the fertility of male rats (Jackson, Fox and Craig, I 96 r) and, more recently, the sterility induced has been shown to be due to the induction of "dominant lethal " mutations in post-meiotic cells (Partington and Jackson, i 963).

Preliminary studies of the fertility of male mice treated with methyl methanesulphonate (Partington and Jackson, unpubl.) indicated that spermatogenic cells in the mouse were similarly susceptible, with the maximal effect occurring in matings during the second week after treatment. Thus, since the majority of the other studies of chemical mutagenesis in mammals have been made in the mouse, an investigation of the mutagenic effects of methyl methane sulphonate in this species was undertaken. This paper presents the results of that investigation.

\section{MATERIALS AND METHODS}

The same stock was used as in previous experiments with triethylenemelamine (Bateman, 1960). The mice were $F_{1}$ hybrids between two closed stocks each segregating for coat colour genes $a, b$ and $c$. The animals show high fertility with low incidence of pseudopregnancy and lethal implantations. Males 2-3 months old and weighing approximately $40 \mathrm{gm}$. were injected intraperitoneally with fresh solutions of methyl methanesulphonate in saline. Two dose levels $(50 \mathrm{mg} . / \mathrm{kg}$. and Ioo mg. $/ \mathrm{kg}$.) were used, and control animals were injected with saline only. Groups of four males were used.

Immediately following injection each male was placed with four virgin females which were replaced at seven-day intervals. Vaginal plugs were recorded and females were dissected on the thirteenth day of pregnancy. The following information was recorded: number of corpora lutea (CL); total implantations (IMP); early deaths or deciduomata (ED) and late deaths with remains of foetus (LD). The abbreviations used are the same as in a previous paper (Bateman, 1960). Late deaths were so infrequent that they were included with ED as the total of dead implants. Several parameters are available for assessing the effects of the drug. 
The proportion of dead implants $\frac{E D+L D}{I M P}$ is the most specific for dominant lethal mutation (i.e. mutation in the sperm which kills the fertilised egg).

The discrepancy between IMP and CL (pre-implantation loss = PRE) has two distinct contributions: one from early-acting dominant lethal mutations and the other from unfertilised eggs. Whenever a treatment is liable to influence the fertilisation rate (by oligospermia or azoospermia), $\frac{\mathrm{PRE}}{\mathrm{GL}}$ is not a reliable indication of mutation rate.

Subject to this limitation, the ratio $\frac{P R E+E D+L D}{C L}$ has the advantage of including all lethal mutations except those which kill an entire litter before implantation, thereby producing pseudopregnancy (PSP). Pseudopregnancy is found in control matings and tends to be erratic in frequency, but when PRE is running at a very high level a corresponding increase in the incidence of PSP may be expected.

Finally, one can convert the dissection data at the thirteenth day into litter sizes that would be expected if all live foetuses came to full term. This estimated " litter size" is presented for comparison with earlier data (Jackson, Fox and Craig, 196r) where litter size was the main criterion of the effect of a sterilising drug.

The first run consisted of matings in weeks $1-3$, whilst in the second run at the same dose levels, attention was concentrated on weeks 4 and 5 to detect any dominant lethal mutations induced in spermatocytes. In addition, testes of treated animals were examined histologically and cytologically. For these studies, three animals, one at each dose level and one control were killed fifteen days after treatment. Material for smears was fixed and stained in acetic orcein and for sections in formol saline and Helly's fluid. Sections were cut at $7 \mu$ and stained in Periodic-acid Schiff and hæmatoxylin.

\section{RESULTS}

\section{(a) First run}

The matings from the first 2 weeks showed comparable mutation frequency, but there were no mutations in the third week. A more detailed analysis of the first 2 weeks revealed considerable variation during each week, the incidence of dominant lethals rising during the first week and falling during the second. The data from the treated males were therefore arranged in four periods of 3 and 4 days alternately (table I and fig. I). Individual males at the same dose levels gave similar responses, and the apparent heterogeneity of response observed initially was found later to be due to variation in day of mating.

Using $\frac{\text { ED }+ \text { LD }}{\text { IMP }}$ as the best criterion of dominant lethal mutations, both doses gave a peak response during the second half of the first week and the first half of the second, the response being approximately proportional to dose (table I and fig. Ia). There was no effect in the third week. A similar though less clear-cut response was shown for $\frac{\mathrm{PRE}}{\mathrm{CL}}$ (fig. $\mathrm{I} b$ ) and combining both statistics, as $\frac{\mathrm{PRE}+\mathrm{ED}+\mathrm{LD}}{\mathrm{CL}}$ (fig. Ic) also gave the expected response. A large increase in the middle of the first fortnight was observed when PSP (fig. Id) was 
DOMINANT LETHALS IN MICE

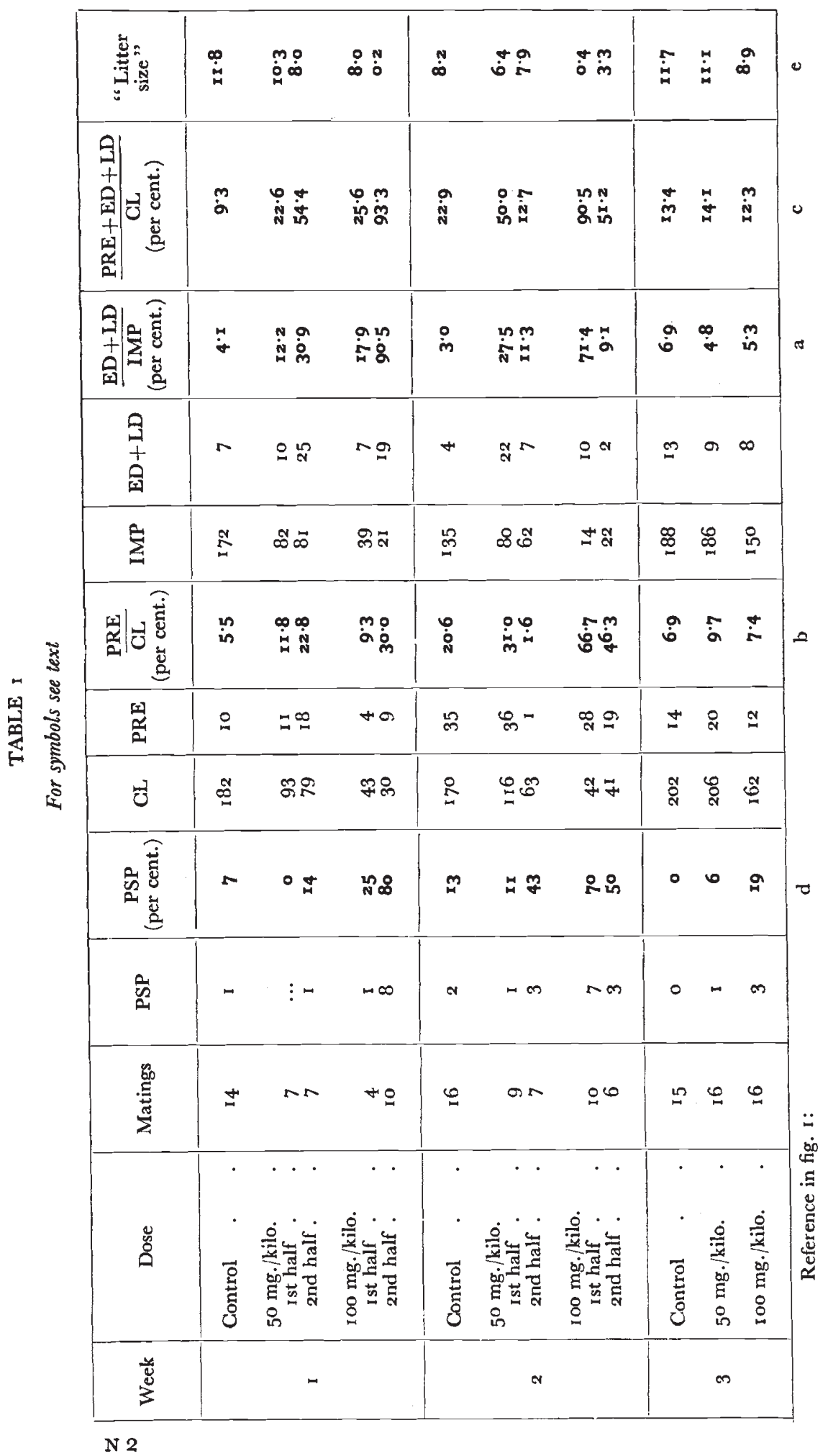



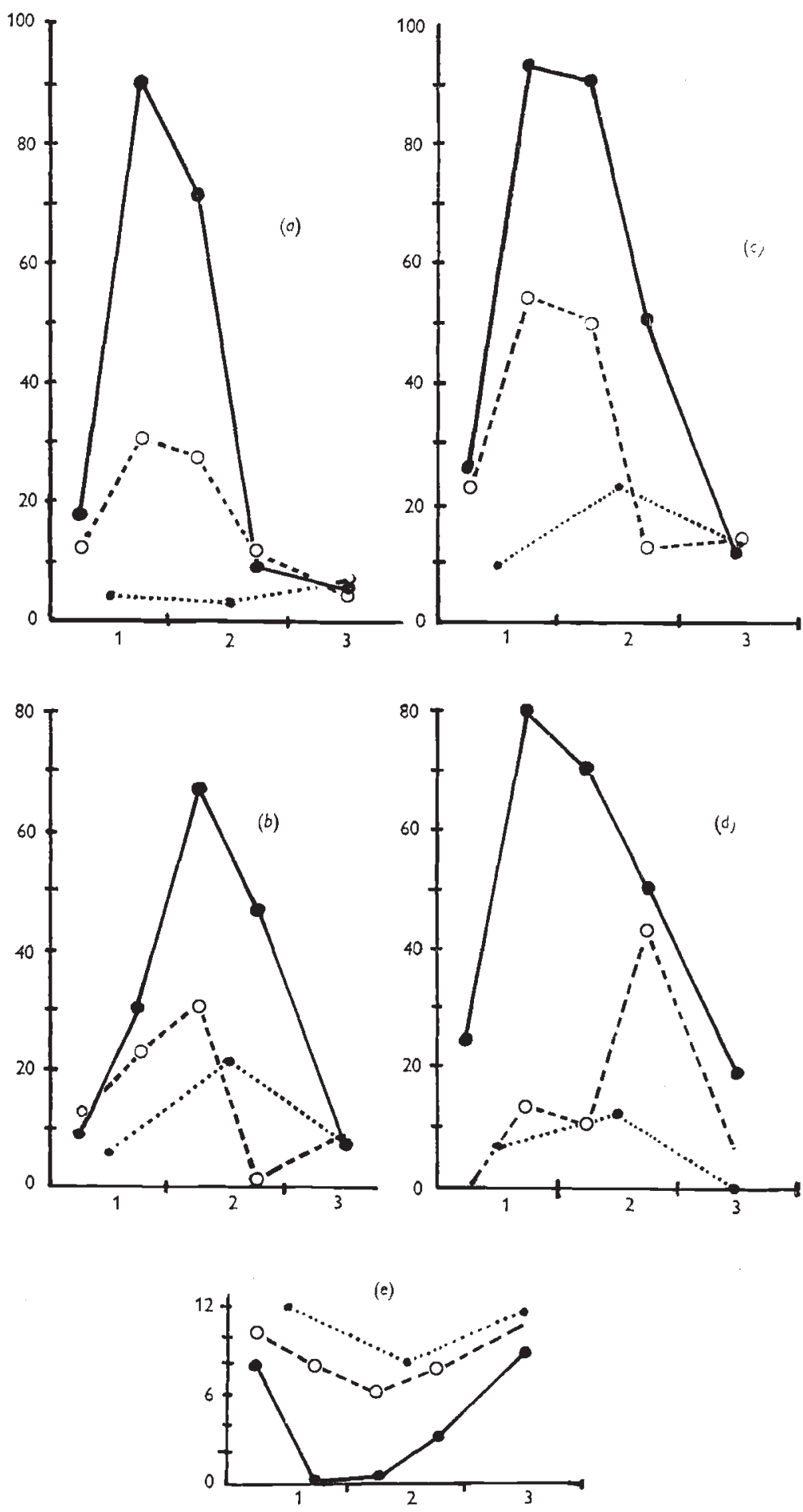
represented as a percentage of matings, but as would be expected from its low sensitivity, this is almost confined to the higher dose level (roo mg./kg.).

The estimated " litter size" is shown (fig. I $e$ ) (total progeny/number of matings including pseudopregnancies). But this is also insensitive. Whereas $100 \mathrm{mg} . / \mathrm{kg}$. shows a clear response, $50 \mathrm{mg}$. $/ \mathrm{kg}$. shows little effect, although a distinct increase in dominant lethal implants $\left(\frac{E D+L D}{I M P}\right)$ at this dose level was demonstrated.

\section{(b) Second run}

Some experiments in progress in this laboratory using methyl methanesulphonate on Drosophila males have indicated a strong sterilising effect on spermatocytes. In addition, histological studies of the testes of male rats after treatment with the same drug have demonstrated considerable numbers of anaphase bridges. At the first meiotic metaphase their incidence remained significantly above control levels up to i9 days post injection (Partington, unpubl.). Mouse spermatocytes, producing spermatozoa utilised in the fourth and fifth weeks would therefore be expected to show some sensitivity to the drug in terms of dominant lethals. Weeks 4 and 5 , however, showed the control level for dominant lethals $\frac{E D+L D}{I M P}$ at both doses (table 2, fig. 2a). It can be concluded that no mutations had been recovered from spermatocytes. The same similarity to the controls was shown for $\frac{\mathrm{PRE}}{\mathrm{CL}}$ and PSP (fig. $2 b$ and $d$ ) indicating that the rate of fertilisation was also normal, in spite of the abnormal histology of the testis. There is, however, a trend of increasing $\frac{\mathrm{PRE}}{\mathrm{CL}}$ with increasing dose in week 4 , but in view of the erratic nature of this parameter even in control matings, little importance can be attached to it.

FIG. 1.-Various parameters indicating the incidence of dominant lethal mutation in matings during the first three weeks after injection of the male with MMS. For the first two weeks, separate estimates have been made for the first and second halves of each week. Graphs $(a)-(\ell)$ represent the parameters indicated by those letters in table 1 , viz.

(a) $\frac{\mathrm{ED}+\mathrm{LD}}{\mathrm{IMP}}$,
(b) $\frac{\mathrm{PRE}}{\mathrm{CL}}$
(c) $\frac{\mathrm{PRE}+\mathrm{ED}+\mathrm{LD}}{\mathrm{CL}}$,
(d) $\mathrm{PSP}$,
(c) "litter size". $100 \mathrm{mg} . \mathrm{kg}$. O $\quad \ldots \mathrm{O}_{5} \mathrm{mg} . \mathrm{kg}$. 
M. PARTINGTON AND A. J. BATEMAN

\begin{tabular}{|c|c|c|c|c|c|c|c|c|}
\hline 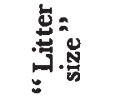 & $\dot{H}$ & $\stackrel{\circ}{\dot{m}}$ & $\stackrel{\infty}{\oplus}$ & 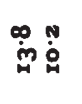 & $\dot{d}$ & $\stackrel{\infty}{\dot{\infty}} \stackrel{\vec{\phi}}{\dot{\phi}}$ & ఏे & केّ \\
\hline 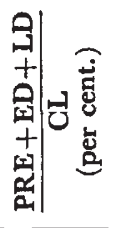 & $\hat{\dot{m}}$ & 荌家 & $\underset{m}{\dot{m}}$ & $\begin{array}{l}m \\
\dot{w} \\
\dot{w}\end{array}$ & $\hat{i n}$ & 品 & $\dot{\dot{b}}$ & 禹品 \\
\hline 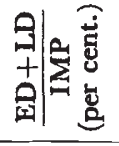 & $\hat{\text { in }}$ & $\hat{\dot{\Delta}}$ & $\ddot{a}$ & $\stackrel{m}{m} \underset{\dot{\infty}}{\dot{m}}$ & in & is in & $\stackrel{\infty}{i m}$ & 穴 \\
\hline $\begin{array}{l}0 \\
9 \\
+ \\
0 \\
0\end{array}$ & in & $\alpha^{\infty}$ & $=$ & $\stackrel{+}{*}$ & $\theta$ & $\infty \infty$ & 0 & $\Sigma^{N}$ \\
\hline$\sum_{i=1}^{B}$ & $\infty$ & $\infty^{\infty}$ & $\bar{\Xi}$ & ్ㅜㅇ & $\mathscr{6}$ & 홈욤 & $\stackrel{\infty}{\stackrel{0}{口}}$ & పేర్లు \\
\hline 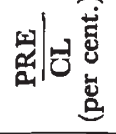 & $\stackrel{+}{\dot{\infty}}$ & 禹号 & $\tilde{j}$ & in $\underset{\text { in }}{\infty}$ & 吕 & $\begin{array}{l}\infty \\
\dot{H} \\
\dot{H}\end{array}$ & $\ddot{\omega}$ & 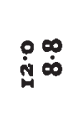 \\
\hline 舆 & $\infty$ & a & 0 & $+\leftrightarrow$ & ํำ & ส के & $=$ & $\mathscr{\sigma}_{\pi}=$ \\
\hline ્ુ & 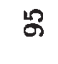 & $\mathscr{\infty}$ & $\widehat{s}$ & สํ & $\stackrel{\infty}{\infty}$ & ఫ్రాळ్ & $\underset{7}{8}$ & $\hat{\sigma}$ \\
\hline 点莕 & 0 & 오 & 。 & ㅇ & $\sim$ & $\infty \sim$ & I & $0 \tilde{N}$ \\
\hline 宊 & 0 & $0 \mathrm{in}$ & 0 & $0-$ & - & -- & N & $0 \mathrm{~m}$ \\
\hline 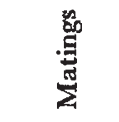 & & $N$ & $\infty$ & $\infty 0$ & 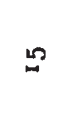 & $= \pm$ & 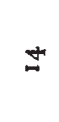 & $\mathscr{I}$ \\
\hline 茄 & 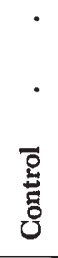 & 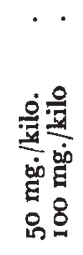 & 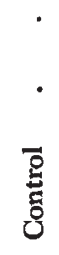 & 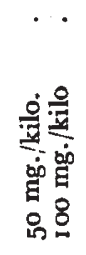 & $\begin{array}{c}\cdot \\
. \\
\text { 롱 } \\
\text { हैं }\end{array}$ & 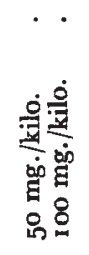 & 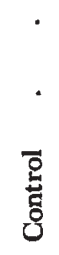 & 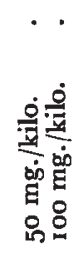 \\
\hline 总 & & * & & $m$ & & + & & n \\
\hline
\end{tabular}



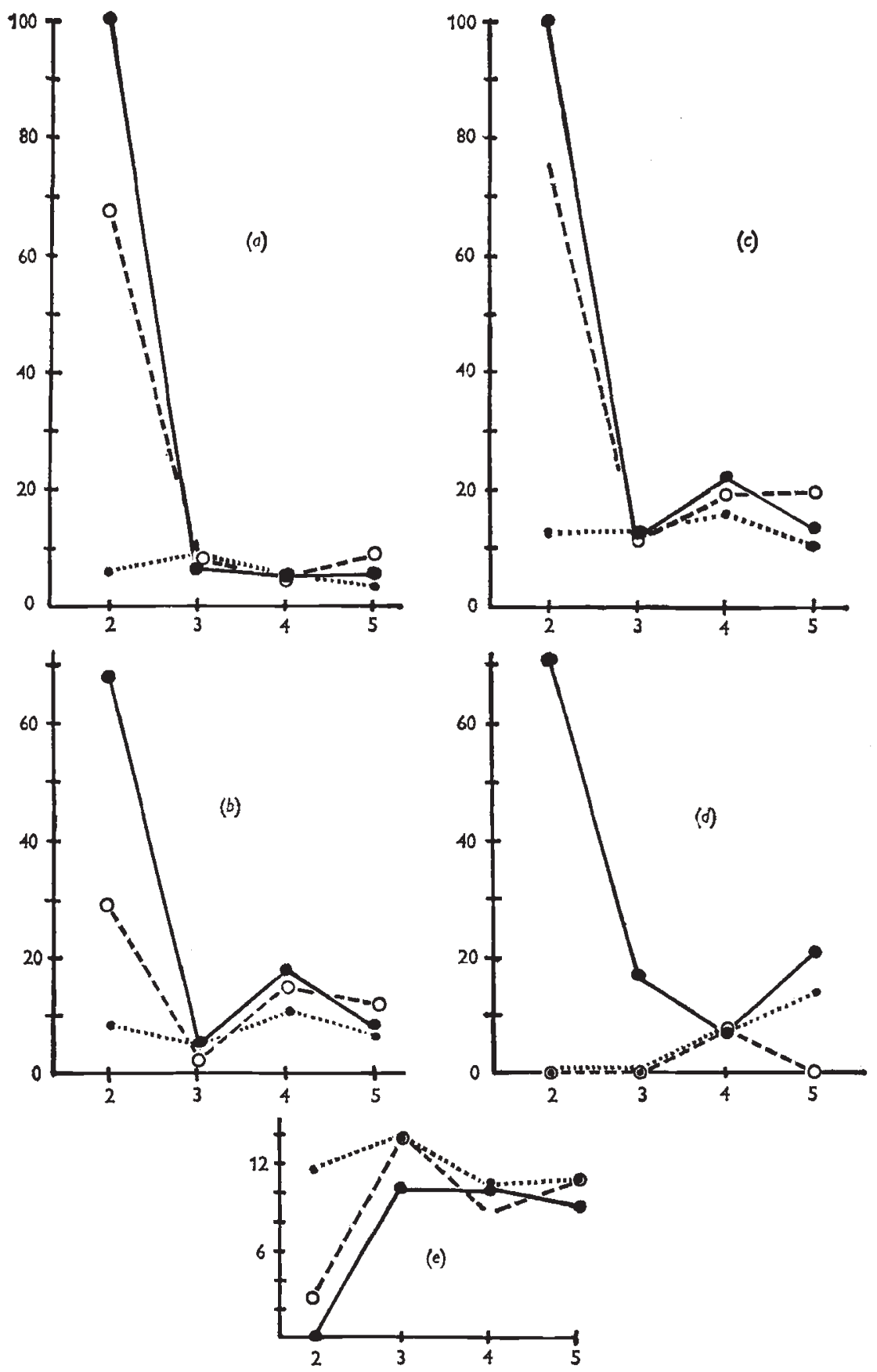

Fig. 2.-As fig. I except that the observations extend over weeks 2 to 5 inclusive following injection. 
Examination of testis smear preparations (made 15 days after treatment) showed many kinds of abnormally shaped mature sperm heads in animals receiving $100 \mathrm{mg}$. $/ \mathrm{kg}$., including bunches of sperm with intertwined tails, suggesting that some agglutination may have taken place, and sperm heads of nearly normal shape with their tails coiled round them. There were very few mature sperm which looked fully normal. The earliest spermatid stages (prior to elongation of the nucleus) were apparently normal. It can be assumed that the extreme malformations in older sperm, though they may only appear as metamorphosis advances, are the result of damage to spermatocytes present at the time of treatment. After $50 \mathrm{mg}$. $/ \mathrm{kg}$. few abnormalities were found and smears closely resembled the control. On the basis of these smears one would expect to find sterility in week 4 matings of mice receiving $100 \mathrm{mg} . / \mathrm{kg}$.

Histological examination showed depletion of spermatocytes in Stages XI and XII and of early spermatids in Stage I-III by 15 days after $100 \mathrm{mg}$. $/ \mathrm{kg}$. suggesting an action on late spermatogonia. The depletion is, however, transient and patchy in distribution. No histological effects could be detected after $5^{0} \mathrm{mg} . / \mathrm{kg}$.

\section{DISCUSSION}

The duration of the testicular phase of spermatogenesis in the mouse can be taken as $34.5 \pm 1$ day (Oakberg, 1956 $a$ and $b$ ) and an additional 7.5 days are required for passage of the spermatozoa through the epididymis and vas deferens (Sirlin and Edwards, 1957a). In the rat, the testicular phase occupies 48 days (Leblond, Clermont and Messier, 1959) and the epididymal phase approximately 15 days (Macmillan and Harrison, I955).

The maximal incidence of "dominant lethal" mutations in the mouse occurred in the second half of the first, and first half of the second week. On the basis of the known timing therefore, this hypersensitive period would be the result of damage to epididymal spermatozoa and late stages of spermatid maturation in the testis. There was also a definite but less marked increase in mutation rate in the first half of the first week and latter half of the second, particularly at the higher dose (table I). This would correspond with an action on spermatozoa in the cauda epididymis and vas deferens and spermatids with developing acrosomes respectively.

In fertility studies in the rat (Jackson et al., 196I) maximal sensitivity was found in the second and third weeks; a single dose of $5^{\circ}$ $\mathrm{mg} . / \mathrm{kg}$. causing sterility at this time. The most susceptible cells would therefore be epididymal spermatozoa and late spermatids. Thus, when the difference in duration of spermatogenesis in the two species is taken into account, their cell sensitivity to methyl methanesulphonate appears to be very similar.

Histological and cytological studies indicated considerable damage to cells in spermatocyte stages after $100 \mathrm{mg}$. $/ \mathrm{kg}$. Such damage would 
imply that there is a marked reduction in the number of viable spermatozoa in the ejaculate, but this appears to be still consistent with normal fertility. Observations in support of this premise have been made by Bateman (1958). About half the matings of male mice in weeks 6 and 7 after 2oor X-rays produced litters and these were about half the normal size although examination of the uteri of mated females revealed that the males were suffering from severe oligospermia.

Attempts to detect dominant lethal mutations induced in spermatocytes (weeks 4 and 5) failed. Many such mutations must be eliminated in the process of maturation to spermatozoa, and the malformed sperm observed illustrate one mode of this elimination. Affected cells are not, however, always eliminated, since dominant lethals have been recovered from mouse spermatocytes after X-rays (Bateman, 1958). Two kinds of potentially dominant lethal damage may thus be considered to be sustained by spermatocytes. The first, such as occurs with X-rays, is transmitted by the sperm and kills the eggs, whilst the second produces malformed spermatozoa which are eliminated prior to fertilisation, a process which occurs after methyl methanesulphonate and probably also after X-rays. Only by detailed cytological studies of treated spermatocytes could one hope to distinguish between these different actions.

Methyl methane sulphonate therefore induces dominant lethals in the mouse, mainly in early epididymal spermatozoa and late spermatids. Earlier spermatids and spermatozoa in the vas deferens show a lower sensitivity but no lethals were recovered from spermatocytes. In this respect the action of methyl methanesulphonate closely resembles that of two monofunctional agents studied in the rat, i.e. methyl ethane sulphonate and ethyl methanesulphonate (Partington and Jackson, I963). A similar dose-response relationship was also found for these compounds. The monofunctional agents differ markedly however from the bi- and polyfunctional agents studied, i.e. Busulphan (Partington and Jackson, I963) and triethylenemelamine (Bateman, I960) in that they have relatively little effect on pre-meiotic cell stages. It seems unlikely that such differences can be explained on the basis of failure to reach the cells since methyl methane sulphonate has been shown to affect spermatogonia (Partington et al., I963), and spermatocytes, but it is far less effective in this respect than Busulphan.

\section{SUMMARY}

Male mice were injected with doses of $50 \mathrm{mg} . / \mathrm{kg}$. and $100 \mathrm{mg} . / \mathrm{kg}$. of methyl methanesulphonate in saline, and together with controls were mated for the following 5 weeks. Dominant lethal mutations were confined to the first 2 weeks' matings, the highest incidence being in the middle of this period. This result is interpreted as due to high sensitivity of epididymal sperm and maturing sperm in the seminiferous tubules. Early spermatids and pre-meiotic stages yielded no 
dominant lethal mutations. The high proportion of abnormal sperm seen in smear preparations after Ioo mg./kg. had no apparent effect on fertility.

\section{REFERENCES}

BATEMAN, A. J. 1958. Mutagenic sensitivity of maturing germ cells in the male mouse. Heredity, 12, $213-232$.

Bateman, A. J. 1960. The induction of dominant lethal mutations in rats and mice with triethylenemelamine (TEM). Genet. Res., I, 381-392.

GATTANACH, B. M. I959. The sensitivity of the mouse testis to the mutagenic action of TEM. Z. Vererb., go, I-6.

CATTANACH, B. M., AND EDWARDs, R. G. I958. The effects of TEM on the fertility of male mice. Proc. Roy. Soc. Edin. B., 67, 54-64.

FALCONER, D. S., SLIZYNSKI, B. M., AND AUERBACH, C. 1952. Genetical effects of nitrogen mustard in the house mouse. 3. of Genetics, 5I, 8I-88.

JACKSON, H., FOX, B. W., AND CRAIG, A. W. I96I. Antifertility substances and their assessment in the male rodent. 7. Reprod. Fertil., 2, 447-465.

LEBLOND, C. P., CLERMONT, Y., AND MEsSier, B. 1959. Durée du cycle d'épithelium séminal du rat. Arch. Anat. micr. Morph. exp., $4^{8,37-56 .}$

MACMillan, E. W., AND haRRISON, R. G. I955. The rate of passage of radio-opaque medium along the ductus epididymis of the rat. Studies on Fertility, 7, 35.

OAKBERG, E. G. I956. Duration of spermatogenesis in the mouse and timing of the cycle of the seminiferous epithelium. Am. 7. Anat., 99, 507-516.

PARTINGTON, M., FOX, B. W., AND JACKSON, H. 1963. Comparative actions of some methane sulphonic esters on the cell populations of the rat testis. Exp. Cell Res. (in press).

PARTINGTON, M., AND JACKSON, H. I963. The induction of dominant lethal mutations in rats by alkane sulphonic esters. Genet. Res. Camb., 4, 333.

SIRLIN, J. L., AND EDWARDS, R. G. I957. Sensitivity of immature mouse sperm to mutagenic effects of X-rays. Nature, I79, 725-727. 